\title{
A patologia como possibilidade estruturante do sujeito: uma releitura da questão phática
}

\author{
Tania Inessa Martins de Resende* \\ José Carlos Castelo Branco Filho**
}

\begin{abstract}
RESUMO - Como produto de estágio supervisionado em saúde mental, este trabalho traz uma reflexão sobre a questão da patologia por outro prisma que não o da doença. A partir da teoria psicanalítica e da psicopatologia existencialista, articulam-se os termos patologia, estrutura e existência, defendendo a idéia de que o pathos é inerente ao ser humano, estando ligado ao modo afetivo que cada indivíduo constrói para estar no mundo. Neste sentido, o delírio, por exemplo, é apresentado como resultado de uma tentativa de organização psíquica, como efeito derivado da tentativa do sujeito de se defender de uma dor insuportável.
\end{abstract}

Palavras-chave: Pathos, psicopatologia, saúde mental, estruturação, existência.

\section{The pathology as a subject's structure possibility: a rereading of the phática matter}

\begin{abstract}
As a product of supervised training in mental health, this assay is a reflection on the matter of the pathology trough another prism that is not the disease. From the psychoanalytic theory and the existentialistic psychopathology, the terms pathology, structure and existence articulate themselves defending the idea that pathos is inherent to the human being, being connected to the affective way that each individual built of to be in the world. In this sense, the delirium, for example, is presented as a result of a psychic organization tentative, as a derived effect of a person's self-defense of an unbearable pain.
\end{abstract}

Key words: Pathos, psychopathology, mental health, structure, existence.

\footnotetext{
* Psicóloga, psicanalista, membro do Percurso Psicanalítico de Brasília, mestre em Psicologia Clínica pela UnB e professora de Psicopatologia e Orientação de Monografia, no curso de Psicologia do UniCEUB. E-mail: tania@hades.com.br

** Licenciado em Psicologia, aluno do $10^{\circ}$. semestre de Psicologia do UniCEUB e aluno do Curso de Formação em Abordagem Centrada na Pessoa, no Centro de Psicologia Humanista de Brasília.E-mail: castelobranco@ brturbo.com
} 
"Psicopatologia não consiste só em fazer o estudo da patologia do psíquico ou em fazer o estudo psicológico do patológico. Consiste em realizar a articulação do pathos, entendido como a disposição afetiva fundamental que move o sujeito constituindo-o na sua humanidade, com o psíquico"

(Martins, 1994).

\section{Algumas observações iniciais sobre a relação teoria-prática}

O tema do presente texto foi desenvolvido a partir de um trabalho mútuo de estágio e supervisão em uma instituição de saúde mental, a saber, um hospital-dia responsável por oferecer serviços voltados para o atendimento e acolhimento de psicoses e neuroses graves. A experiência produziu ressonâncias teóricas que foram retomadas na própria experiência e tematizadas nas supervisões. "A prática é elaboração viva, a teoria é diretamente posta à prova, a marcha para diante é a mesma e as dificuldades andam lado a lado" (Laplanche, 1992, p. 162). Consoante esta visão acerca da relação teoria-prática, a situação de contato com pacientes, já tradicionalmente considerados como portadores de um prognóstico negativo e inexorável, exigiu de nossa parte uma tematização que viabilizasse uma atuação que concretamente visasse ao terapêutico, questionando esse prognóstico. A supervisão, neste sentido, configura-se como um primeiro espaço de proximidade entre teoria e prática, embora esta relação ainda esteja longe de ter sido caracterizada (Resende \& Celes, 2000).

O presente texto fundamenta-se, contudo, em um momento diferenciado desta teia intrincada teoria-prática. Trata-se agora de permitir que a experiência prática de estágio e supervisão, já incluindo nesta sua específica relação com o trabalho teórico, articule-se de uma outra maneira com a teoria.

Uma questão adquiriu um contorno privilegiado: a associação moderna de patologia com doença. Quando se pensa em uma patologia, logo remete-se à idéia de doença, de que algo não está bem; no entanto, outra possibilidade foi gerada a partir dessa experiência: perceber a patologia como uma busca pela saúde, pela regulação, como algo estruturante. Será, portanto, o percurso específico deste texto articular a idéia de patologia com estruturação e existência, o que será feito com o auxílio da metapsicologia psicanalítica e da abordagem existencialista em psicopatologia.

\section{Repensando o pathos}

Em primeiro lugar é preciso entender o que vem a ser o pathos e o que ele tem a ver com a idéia de patologia, desconstruindo a redução de pathos a doença. 
Segundo Martins (1994), o termo pathos se tornou um radical que, quando utilizado com qualquer outra palavra, imputa a essa a idéia de doença; todavia, o conceito de pathos traz consigo possibilidades e problemas com uma amplitude maior que o sentido de doença. Em se tratando de uma dimensão essencialmente humana, esse termo "seria compreendido como uma disposição originária do sujeito que está na base do que é próprio do humano" (p. 5). Dessa forma, pathos faz parte de todo o universo do ser, atravessando a completude da dimensão humana, pertencente à descoberta e à infindável investigação do que é o Homem.

Martins (1994) também traz a idéia de que o pathos deve ser entendido como uma disposição afetiva fundamental, que é organizadora e propulsora do destino humano, ou seja, é fundamental na tomada de decisão com relação à posição de vida do sujeito, tornando-se em muitos casos o que move e dá vida a esse sujeito. Muitas vezes essa disposição leva o sujeito a viver uma desarmonia ou falta de harmonia (disposição), que acaba por tornar-se um elemento mais evidente em sua existência. Essa desarmonia é característica das formas essenciais de destinos pathológicos humanos em que o sofrimento toma espaço. "O pathos contém esta possibilidade de perda de harmonia na evolução e nos destinos diferentes dos seres humanos, especialmente dos chamados doentes mentais, mas também contém as formas mais sublimadas de existência" (p. 8).

O pathos está ligado ao modo afetivo que cada indivíduo constrói para estar no mundo, dizendo respeito não somente às questões de desequilíbrio, mas estando presente também no dia-a-dia do sujeito e de sua cultura. Essa disposição subjetiva individual resultará na maneira como o sujeito lidará com a realidade: se com mais ou menos sofrimento, se com mais ou menos contato com essa realidade e de maneira mais rígida ou flexível.

Em uma direção semelhante, embora não idêntica, Berlinck (2000) coloca que, além de sofrimento, pathos também dá origem às palavras "paixão" e "passividade". Dessa forma, para o autor, o sujeito é constituído e coincide com o pathos, que é sofrimento, paixão e passividade. Ele acrescenta que quando pathos acontece, algo da ordem do excesso, da desmesura, toma conta da "cena" sem que o eu possa tomar posse desse acontecimento, a não ser como paciente, como ator.

Portanto, ainda segundo Berlinck (2000), pathos não existe se não houver mobilidade, imperfeição ontológica. "Se assim for, pathos é um dado do mundo sublunar e da existência humana" (p. 20). Pathos designa o que é pático, o que é vivido e sendo assim, o que pode ser transformado em experiência, considerandoo como algo que enriquece e alarga o pensamento. Pathos transforma-se em patologia, ou seja, um discurso sobre o sofrimento, as paixões e a passividade quando rege as ações humanas. 
Queiroz (2002) compactua com as idéias de Berlinck acrescentando que, na condição de sofrimento passivo que pathos traz, o sujeito é afetado por algo que vem de fora, não tendo origem no corpo. Mas passa necessariamente pelo corpo e expressa-se pela hýbris.

"O esforço feito até o momento foi no sentido de demonstrar como está o pathos na essência mesma do ser humano, e não só na excepcionalidade do adoecer. Na verdade, se fôssemos mais justos, deveríamos indicar que houve uma redução do conceito de pathos ao sentido de doença. (...) Conseguiu-se um conhecimento objetivo que, de tão privilegiado, deixou de lado o sujeito mesmo, objeto de tanto estudo. Por isso se torna premente pensar a questão phática como sendo inerente e fundamental para o Ser, sem que com isso seja excluída a noção fundamental de sofrimento humano. Mas antes de pathos ter sido tomado como doença, a própria noção de adoecimento passou a ser controlada por um outro conceito. Trata-se de confundir pathos com doença e esta, com hýbris. Finalmente, assim, com a concepção de doença, pathos se torna hýbris sem o saber, como se pathos envolvesse somente a aberração, o desvario e a anormalidade. O conceito de hýbris foi identificado como sendo campo de estudo do pathos contemporâneo. (...) Hýbris seria o ultraje, a aberração, relacionando-se estreitamente com algo ofensivo, insultuoso e injurioso...". (Martins, 1994, p. 13)

Dessa forma, ainda segundo Martins (1994), tudo o que possa ser identificado como sendo pathos pertence ao ser humano, sendo o adoecer também uma possibilidade desse Ser. Por este motivo, os limites do patho-lógico devem ser interpretados para além dos sentidos tradicionais que delimitam a noção de patológico na medicina atual.

Não se trata aqui de fazer apologia às patologias, anular o sofrimento e a angústia humanos que se presentificam, por exemplo, nas experiências de alucinação e delírio. Todavia, é possível pensarmos a patologia como a forma que o sujeito encontrou para estar no mundo, resgatando a história de sua subjetividade.

\section{Pathos e estruturação}

Pathos, como foi discutido, pode ser entendido como estando ligado ao modo afetivo que cada indivíduo constrói para estar no mundo e que surge, justamente, do ponto de vista da teoria psicanalítica, da tentativa do aparelho psíquico de lidar com o corpo e a cultura desse indivíduo (Martins, 1994). Dessa forma, podese pensar que o sintoma não é meramente algo patológico no sentido estrito de hýbris, é também da ordem do estruturante. 
A partir do princípio do cristal descrito por Freud, encontra-se tematizada a capacidade do psicopatológico em desnudar a estrutura, ou seja, o patológico é capaz de deixar visível a composição estrutural do sujeito. Vale dizer que existe, na concepção psicanalítica, uma relação recíproca entre a estrutura clínica e a psicopatologia. É no pathos que o sujeito reconhece sua verdadeira constituição. Trata-se, portanto - o que se tornou evidente na experiência clínica - da necessidade de ultrapassar a concepção nosográfica, indo além das considerações puramente descritivas e classificatórias. No interior de cada linhagem estrutural persiste uma variedade de possibilidades, o que nos leva à idéia de uma ação transformadora da estrutura clínica. Uma série de percursos impostos pela história do sujeito vai construir uma teia complexa de significações, escapando da configuração de limites impostos pela estrutura. Pathos, como excesso, não comporta um fechamento em si mesmo: significa dizer que a estrutura patológica se confunde com a própria subjetivação, sendo a possibilidade do sujeito em um dado tempo...

A construção do delírio, por exemplo, é uma tentativa de reorganização do funcionamento mental do indivíduo; é um esforço que o aparelho psíquico do sujeito realiza no sentido de lidar com a desorganização vivenciada pelo sujeito. A realidade que se impõe ao sujeito é tomada como intolerável, exigindo a construção de uma nova realidade onde encontre um espaço para si.

Nasio (2001), retomando a idéia freudiana de que "o delírio é uma tentativa de cura" (p. 54), argumenta que no famoso estudo do caso Schreber, Freud demonstrou que a construção delirante é resultado da tentativa de organização psíquica empreendida pelo psiquismo de Schreber que não "suporta" a idéia que um dia em semi-vigília lhe ocorreu: "seria muito bom ser uma mulher submetendose ao coito" (p. 45). Schreber indigna-se com tal idéia e a repugna veementemente; dessa forma, foi preciso que ele encontrasse uma maneira de resolver esse conflito. É justamente neste momento que a psicose entra em cena como uma tentativa de ligação: "essa idéia indigna nunca me haveria ocorrido sem uma intervenção externa" (idem, p. 47).

O delírio ou a alucinação, entendidas do ponto de vista psíquico, não são conseqüências imediatas de uma dada causa, mas efeitos derivados da tentativa do sujeito de se defender de uma dor insuportável. Alguns doentes mostram-nos isso, como um deles disse a Storch (1965), citado em Scharfetter (1997, p. 245): "Eu construo o meu próprio mundo, a fim de superar tudo o que é lamentável". Outro dizia a Kretschmer (1963) também citado em Scharfetter (1997, p. 245): "Você pode dizer o que quiser da realidade, eu acho-a horrível".

Scharfeter (1997) afirma que "o doente com delírio de perseguição experimenta uma intensa relação com os outros (ainda que com caráter negativo) e através dela sai do seu isolamento: 'é preferível ser perseguido do que estar só'; ou que 
o delírio de perseguição ajuda a evitar também uma proximidade insuportável, e que o doente, no seu delírio de redenção e de cura, se preocupa altruisticamente pelas outras pessoas, dando ambos lugar a uma promoção do papel social" (p. 245).

Para Freud, a psicose é uma doença da defesa; “é a expressão mórbida da tentativa desesperada que o eu faz para se preservar, para se livrar de uma representação inassimilável, que, à maneira de um corpo estranho, ameaça sua integridade" (Nasio, 2001, p. 36). Nesta mesma direção, Dahlke \& Dethlefsen (2002) afirmam que a função do sintoma é fazer desaparecer, na maioria das vezes, o elemento que está causando a perturbação, o desequilíbrio.

Desde Freud (1895), em Estudos sobre a histeria, podem-se observar evidências dessa peculiaridade das patologias; quando ele demonstrou que, ao se retirar o sintoma de um paciente, ele reaparecia em outro lugar. O sintoma pode ser pensado como ocupando o lugar de algo que falta, que está desorganizado ou mesmo insuportável.

Para alguns autores, a própria neurose, em muitos casos, é considerada como uma defesa à psicose. Bergeret (1998) diz que "é comum encontrar organizações estruturais autenticamente psicóticas que se defendem contra a descompensação graças a defesas de modalidade neurótica, mais particularmente obsessiva, por exemplo" (p. 48). O autor afirma, a partir de sua reconhecida experiência profissional no consultório psicológico, que alguns pacientes com o diagnóstico de neurose obsessiva que possuem uma visível manifestação defensiva com complicados e impressionantes rituais, na verdade estão buscando organizar-se e evitar que a desfragmentação psicótica tome conta de seu ser.

Retomando a experiência mencionada no início deste texto, pode-se ilustrar esta idéia. Um paciente, diagnosticado como neurótico obsessivo, quando perguntado sobre as razões pelas quais emitia alguns comportamentos ritualísticos como demorar no banho, dar pulos, andar para frente e para trás e ter uma grande rigidez com horários, sempre respondia da seguinte forma: "Se eu não fizer os rituais não terei harmonia; se não me limpar acho que vai acabar acontecendo uma besteira, uma loucura... fico perturbado" (sic). A partir de uma atividade projetiva, o mesmo desenhou a árvore com uma infinidade de linhas paralelas e horizontais no tronco da mesma que, segundo ele, "são essenciais para segurar a árvore, senão ela desmonta" (sic); durante a conversa sobre os desenhos, o paciente demonstrou uma grande identificação com a árvore, projetando alguns sentimentos e situações vividas por ele na mesma. A despeito do entendimento tradicional acerca da função de proteção dos rituais obsessivos no sentido de aplacar a angústia oriunda das obsessões, o contato clínico e cotidiano com este sujeito parece apontar para uma função estruturante, não meramente defensiva, ainda que também o seja. 
Outro paciente diagnosticado com esquizofrenia tinha o hábito de andar com os braços cruzados e explicava tal comportamento, dizendo: "estou me segurando senão eu me desmonto, eu me perco..." (sic). E, em uma de suas crises, disse: "não adianta eu tentar ser homem... Eu sou mulher!" (sic). Ainda, outra paciente durante uma conversa disse: "Ontem estava pensando e cheguei à conclusão de que não tenho nada na cabeça, então, hoje decidi colocar o chapéu para que pelo menos fora da cabeça eu tenha alguma coisa"(sic). Essas breves referências clínicas revelam a produção de sentidos presentes na vivência sintomática que sugere a presença de pathos para além de hýbris.

\section{Pathos e existência}

Para Sartre, citado em Romero (2001), não importa o que nos foi dado, o importante é o que nós fazemos com o que recebemos; assim, o sujeito se configura e configura seu mundo de um modo concreto, segundo as situações que esteja vivendo numa fase determinada de sua vida.

Segundo Romero (2001), “o mental não é algo que nos acontece apenas dentro da cabeça, sem maior relação com o mundo fora. Pelo contrário: o mental está intimamente direcionado para o mundo; é o mundo refletido de certa maneira, numa determinada pessoa" (p. 57). Cada pessoa é o que pode ser, com todas suas possibilidades e limitações; toda vivência é uma forma de relação que o sujeito estabelece com os diversos objetos que constituem seu mundo.

Dalgalarrondo (2000), retomando um aspecto da leitura existencialista da psicopatologia, afirma que o "doente" é visto como uma "existência singular". "O ser é constituído pela experiência particular de cada sujeito, na sua relação com outros sujeitos, na abertura para a construção de cada destino pessoal" (p. 29). Dessa forma, a doença mental seria entendida como um modo particular de existência, uma forma trágica de ser no mundo, de construir seu caminho.

O mundo de uma pessoa é uma configuração complexa de relações significativas que, como uma teia de aracnídeo, sustenta sua existência, oferecelhe certas possibilidades e também a aprisiona. Posição esta próxima da defendida por Berlinck (2000) quando afirma que pathos torna-se patologia quando o sofrimento e a passividade passam a reger as ações humanas.

A loucura "pode ser entendida pelo lado social, (...) como uma incapacidade do indivíduo para adaptar-se às exigências e solicitações da realidade coletiva ou interpessoal - inadaptação que o leva a uma ruptura com essa realidade" (Romero, 2001, p. 301). Podemos, dessa forma, utilizando um outro referencial teórico, entender a loucura como um refúgio no imaginário quando a realidade resulta para o sujeito completamente intolerável. 
Romero (2001) discute um ditado que apresenta como o refúgio no imaginário pode servir tanto para o neurótico quanto para quem já não acerta conviver dentro dos padrões de sua comunidade:

"O neurótico constrói castelos no ar sem tentar nunca neles morar; o louco inventa igualmente castelos no ar para neles habitar" (p. 303).

Com este ditado, pode-se perceber que cada indivíduo constrói e habita um mundo de acordo com sua experiência e segundo a feição e a natureza de seus conflitos. O autor reflete que:

"Os dois tipos alimentam fantasias insustentáveis, incompatíveis com o princípio de realidade. Os dois tipos agem segundo objetivos errados, mas o alcance do extravio marca a diferença. O intuito do neurótico permanece em perpétua distância de seu cumprimento; talvez como miragem e alívio parcial de suas dores. Não chega ao abandono de sua base de sustentação; só que essa base é muito frágil. (...) O supercontrole do obsessivo, com sua necessidade de ordem e programação, delata igualmente essa fragilidade. E o histérico? Vive na representação e na inautenticidade. (...) O psicótico vai mais longe; seu desarraigo é maior; inventa castelos no ar para neles morar" (idem, p. 304 e 305).

Pode-se pensar que pathos e estrutura e pathos e subjetivação se atualizam na existência única de cada sujeito, sendo os sentidos construídos na história psíquica e existencial de cada subjetividade.

Essa nova forma de entender o pathos, como disposição afetiva fundamental, e assim a patologia, faz com que se tenha um novo entendimento sobre a "normalidade" e a "loucura" e, conseqüentemente, um novo modo de pensar a intervenção terapêutica em saúde mental.

A loucura, segundo Teixeira (1996), passa a ser entendida, também como uma problemática biopsicossocial e é a partir daí que se deve pensar as intervenções para o tratamento da doença mental. Afinal, congruente com o que foi discutido ao longo do texto, o adoecimento mental deve ser entendido como "eminentemente um fato humano e que as suas fronteiras são as da subjetividade" (Filizzola, 1994, p. 19). Teixeira (1996) enfatiza que, em nossa prática, lidamos com sujeitos culturalmente reconhecidos como loucos e não com uma coisa conhecida como loucura ou psicose. Nenhuma forma de entendimento absoluto da loucura continua a ter lugar nesse cenário repleto com a individualidade de cada pessoa. Para Rodríguez (1998), toda e qualquer intervenção terapêutica deve "partir da singularidade do paciente para desenvolver um modelo único a cada caso no qual a intervenção é um elemento que pretende sustentar aquele que falha na dimensão delirante do 
paciente" (p. 146, grifo nosso).

Esta é a psicopatologia que nos interessa, onde, de velhos olhares, passamos a nos enveredar rumo a novas intervenções.

\section{Referências}

BERGERET, Jean. (3ª. ed.) A personalidade normal e patológica. Porto Alegre: Artmed. 261 p., 1998.

BERLINCK, Manoel Tosta. Psicopatologia fundamental. São Paulo: Escuta,. 416p., 2000.

DALGALARRONDO, Paulo. O juízo de realidade e suas alterações (o delírio), In:Psicopatologia e semiologia dos transtornos mentais. p. 132 - 141, 2000. Artes Médicas: Porto Alegre.

DETHLEFSEN, Thorwald \& DAHLKE, Rüdiger. A doença e os sintomas. In: A doença como caminho - Uma visão nova da cura como ponto de mutação em que um mal se deixa transformar em bem. p. 11- 19, 2002. Cultrix: São Paulo.

FILIZZOLA, Carla de Fátima Schinniger. Loucura e a Instituição: "Uma questão de escuta". PSIQUE - Revista do Departamento de Psicologia da Faculdade de Ciências Humanas e Letras - FAHL/ FINP, Ano 4-n ${ }^{\circ}$ 5: 18 - 21, 1994.

FREUD, S. Estudos sobre a histeria. In: Edição Standard Brasileira das Obras psicológicas completas de Sigmund Freud. Rio de Janeiro: Imago, 1895.

LAPLANCHE, J. Novos fundamentos para a psicanálise. São Paulo: Martins Fontes, 174 p., 1992.

MARTINS, Francisco. O que é pathos? In: Psicopathologia I - Fundamentos. p. 2 - 17, 1994. Universidade de Brasília, Instituto de Psicologia, Brasília.

NASIO, Juan-David e cols. Os grandes casos de psicose. Rio de Janeiro: Jorge Zahar. 244p., 2001.

QUEIROZ, Edilene Freire. A pesquisa em Psicopathologia fundamental: Um discurso transdisciplinar. In: Pesquisa em psicopatologia Fundamental. QUEIROZ, Edilene Freire \& SILVA, Antonio Ricardo R. da (orgs.), p. 15 - 25, 2002. Escuta, São Paulo.

RESENDE, T. I. M. \& CELES, L. A. M. Sobre a (não) condução de uma análise. Pulsional Revista de Psicanálise, ano XII, n 137: 72-82, 2000.

RODRÍGUEZ, M. J. Algunas contribuciones al debate sobre la clínica de las psicosis. Revista Latino Americana de Psicopatología Fundamental, vol. 1, nº 4: 138-146, 1998.

ROMERO, Emílio. (3 $3^{\text {a }}$ ed. Rev. e Ampl.) O inquilino do imaginário: Formas de alienação e psicopatologia. São Paulo: Lemos. 331 p., 2001.

SCHARFETTER, Christian. A cerca de uma Psicopatologia Geral. In: Introdução à psicopatologia geral.p. 01 -46, 1997. Climepsi: Lisboa.

TEIXEIRA, Manoel Olavo Loureiro. Algumas Reflexões sobre o conceito de cura em psiquiatria. Cadernos do IPUB, $\mathrm{n}^{\circ}$ 3: 67-75, 1996. 
Envie suas publicações para o Conselho Editorial da revista Universitas - Ciências da Saúde.

$$
\begin{aligned}
& \text { Endereço para envio: } \\
& \text { SEPN 707/907, Campus do UniCEUB } \\
& \text { 70790-075 Brasília-DF }
\end{aligned}
$$

universitas.saude@uniceub.br

Verifique as normas de publicação no final deste número! 